\title{
PERAN AYAH DALAM KEBERHASILAN PROGRAM INISIASI MENYUSUI DINI (IMD) PADA BAYI YANG LAHIR SECARA SECTIO CESARIA
}

\author{
(The Role of Father in Successfulness of Early Breastfeeding \\ Initiation Program to the Newborn with Sectio Cesarea)
}

\author{
Sestu Retno D.A*, Nursalam**, Budi Santoso***, Rachmat H**** \\ *Stikes Pemkab Jombang, Jl. dr. Soetomo No. 75-77 Jombang Jawa Timur 61411 Indonesia \\ **Fakultas Keperawatan Universitas Airlangga \\ ****Fakultas Kedokteran Universitas Airlangga \\ ****Fakultas Kesehatan Masyarakat Universitas Airlangga \\ Email: sestu.retno@yahoo.com
}

\begin{abstract}
ABSTRAK
Pendahuluan: Persalinan secara Sectio Cesaria $(S C)$ merupakan salah satu kendala untuk melakukanInisiasi Menyusui Dini(IMD). Kesiapan ibu yang baru melahirkan untuk memberikan ASInya pada bayi yang baru dilahirkan memerlukan adanya persiapan karena ibu mengalami perubahan peran.Pencapaian peran ibu bisa berhasil bila ibu menjadi dekat dengan bayinya dan mendapatkan dukungan dari ayah.Peran ayah dalam pelaksanaan IMD adalah sangat penting.Keterlibatan ayahi dalam pelaksanaan IMD ini meliputi pemberian dukungan dan interaksi. Ayah merupakan orang terdekat bagi ibu menyusui yang diharapkan selalu ada di sisi ibu dan selalu siap memberi bantuan. Jika ibu mendapatkan kepercayaan diri dan mendapat dukungan penuh dari ayah, motivasi ibu untuk menyusui akan meningkat.Penelitian ini bertujuan untuk mengetahui peran ayah dalam pelaksanaan IMD.Metode: Penelitian ini menggunakan jenis penelitian eksplanatif observasional dengan rancangan cross sectional, bertujuan menggumpulkan data responden untuk menjawab issu strategis yang sedang terjadi, yang menyebabkan ibu postSC tidak melaksanakan IMD. Responden sejumlah $282 \mathrm{ibu}$ post SC yang memenuhi kriteria inklusi dan eksklusi. Tempat penelitian ini dilakukan di ruang operasi (OK) kebidanan rumah sakit Tipe B, yaitu RSUD Jombang dan RSUD Sogaten Madiun. Hasil: Hasil pengujian secara bersama terdapat pengaruh dari variabel dukungan ayah dan interaksi ayah terhadap pelaksanaan IMD.Hasil pengujian secara individu terhadap variabel dukungan ayah terdapat pengaruh terhadap pelaksanaan IMD, sedangkan pada variabel interaksi ayah tidak terdapat pengaruh terhadap pelaksanaan IMD.Pelaksanaan IMD dipengaruhi oleh dukungan ayah sebesar 3,7\%. Diskusi: Ibu yang didukung ayahi lebih termotivasi untuk melaksanakan IMD kepada bayinya.
\end{abstract}

Kata kunci: persalinan sectio cesaria, Inisiasi Menyusui Dini (IMD)

\begin{abstract}
Introduction: Delivery through Sectio Caesaria (SC) is one of the obstacles to doing Initiation of Breast Feeding. The readiness of new mothers to give her milk to the newborns in need of psychological preparation, because the mother has a role change. The achievement of the role of the mother can be successful if the mother close to the baby and get the support from the spouse (husband). Husband's role in the implementation of IMD is very important. Husband's involvement in the implementation of IMD include the provision of support and interaction. The husband is the closest person for breastfeeding mothers who are expected to always be on the maternal side, and are always ready to provide assistance. If mothers gain confidence and full support of her husband, the motivation for breastfeeding mothers will increase.The objective of this study was to know the role of husband in accompanied the mother with section caesarean in implementing of IMD.Methods: This study used observational eksplanatif, with cross-sectional design, the aims were collecting the respondent data to answer the strategic issues which were going on, which caused the post SC women do not implemented the IMD. Respondent: as many 282 post SC mothers who covered the inclusion and exclusion criteria. The study was conducted in the operating room (OK) Type B obstetrics hospitals, namely RSUD Jombang and RSUD Sogaten Madiun.Result: The test results Together showed there was an effect from Spouse support variable and spouse's interaction to the implementation of IMD. Individual test result of spouse support to the effect of implementation of IMD, however variable of spouse's interaction, there was no effect to the implementation of IMD. The implementation of IMD was effected by spouse support as many as 3,7\%.Discussion:The mother that had the support from spouse had a higher motivation in implementation of IMD to the baby
\end{abstract}

Key words: caesarian delivery, initiation of breast feeding

\section{PENDAHULUAN}

Pelaksaanaan Inisiasi Menyusu Dini (IMD) sangat dipengaruhi oleh metode persalinan.Persalinan secara sectio caesaria (SC)merupakan salah satu kendala untuk melakukan IMD. Hal ini berhubungan dengan rasa nyeri akibat luka operasi, pengaruh anastesi, ketidaknyamanan ibu, dan belum keluarnya ASI setelah operasi (Prior, E., Santhakumaran, S., Gale, C., Philipps, L. H., Modi, N., \& Hyde 2012). Meskipun telah dilakukan pemberian anestesi tetapi rasa nyeri masih dirasakan oleh ibu. Seperti yang 
dikemukakan oleh (Padmavathi, P., Jayadeepa, T., \&Babu 2014), dalam penelitiannya menunjukkan bahwa alasan ibu tidak melaksanakan IMD adalah akibat nyeri luka operasi (92\%), ketidaknyamanan (78\%), efek anestesi (74\%). Nyeri postSC apabila tidak segera diatasi dapat menurunkan kemampuan ibu dalam melaksanakan IMD (Storm, 2007).

Penelitian sebelumnya menunjukkan bahwa $S C$ merupakan salah satu kendala untuk melakukan IMD. Hasil penelitian Prior, E., Santhakumaran, S., Gale, C., Philipps, L. H., Modi, N., \& Hyde (2012)menunjukkan adanya hubungan yang negatif antara persalianan secara $S C$ dengan pelaksanaan IMD. Hal ini berhubungan dengan rasa nyeri akibat luka operasi, pengaruh anastesi, ketidaknyamanan ibu, dan belum keluarnya ASI setelah operasi. Seperti yang dikemukakan oleh Padmavathi, P., Jayadeepa, T., \&Babu (2014) dalam penelitiannya menunjukkan bahwa alasan ibu tidak melaksanakan IMD adalah akibat nyeri luka operasi $(92 \%)$, ketidaknyamanan $(78 \%)$, dan efek anestesi (74\%).

Ibu yang baru melahirkan perlu mempersiapkan diri untuk memberikan ASInya pada bayi yang baru dilahirkan, persiapan secara psikologis diperlukan karena ibu mengalami perubahan peran. Berdasarkan teori keperawatan Maternal Role attainmentbecoming a Mather yang dikembangkan oleh Ramona T. Mecer, yang mengemukakan bahwa focus utamadari teori ini adalah gambaran proses pencapaian peran ibu dan proses menjadi seorang ibu. Pencapaian peran ibu bisa berhasil bila ibu menjadi dekat dengan bayinya dan mendapatkan dukungan dari pasangan (suami) termasuk mengekspresikan kepuasan dan penghargaan peran selanjutnya setelah melahirkan (Alligood 2002). Peran suami dalam pelaksanaan IMD adalah sangat penting, karena suami akan turut menentukan kelancaran refleks pengeluaran ASI yang sangat dipengaruhi oleh keadaan emosi atau perasaan ibu. Suami dapat berperan aktif dalam membantu ibu dalam memberikan ASI dengan memberikan dukungan emosional dan bantuan-bantuan praktis lainnya (Roesli 2001).

Kebutuhan kenyamanan fisik termasuk defisit dalam mekanisme fisiologis yang terganggu atau beresiko karena sakit atau prosedur invasif.Kebutuhan fisik yang terlihat seperti nyeri mudah tangani dengan maupun tanpa obat. Standar kenyamanan intervensi diarahkan untuk mendapatkan kembali dan mempertahankan homeostasis (Kolcaba, K., \&DiMarco 2005;Wong, J. Y., \& Earl 2009)

Kebutuhan kenyamanan psikospiritual termasuk kebutuhan untuk kepercayaan diri, motivasi dan kepercayaan agar klien lebih tenang ketika menjalani prosedur invasif yang menyakitkan atau trauma yang tidak dapat segera sembuh.Kebutuhan ini sering dipenuhi dengan tindakan keperawatan yang menenangkan bagi jiwa klien serta ditargetkan untuk trasedensi seperti relaksasi dan distraksi, sentuhan dan kepedulian.Fasilitasi diri untuk strategi menghibur dan kata-kata motivasi. Tindakan ini termasuk intervensi khusus karena perawat sering sulit meluangkan waktu untuk melaksanakannya tetapi apabila perawat menyempatkan diri maka tindakannya akan sangat bermakna. Tindakan ini dapat memfasilitasi klien dan keluarga mencapai transendence (Kolcaba, $\quad$ K., \&DiMarco 2005;Wong, J. Y., \& Earl 2009)

Kebutuhan kenyamanan sosiokultural adalah kebutuhan untuk jaminan budaya, dukungan, bahasa tubuh yang positif, dan caring.Kebutuhan ini terpenuhi melalui pembinaan yang mencakup sikap optimisme, pesan-pesan kesehatan dan dorongan semangat, penghargaan terhadap pencapaian klien, persahabatan perawat selama bertugas, perkembangan informasi yang tepat tentang setiap aspek yang berhubungan dengan prosedur, dan pemulihan kesadaran setelah anastesi. Kebutuhan sosial ini juga termasuk kebutuhan keluarga untuk menghormati tradisi budaya (Kolcaba, K., \&DiMarco 2005; Wong, J. Y., \& Earl 2009)

Kebutuhan kenyamanan lingkungan meliputi ketertiban, ketenangan, perabotan yang nyaman, bau yang minimal, dan keamanan.Ketika perawat tidak mampu untuk menyediakan lingkungan benar-benar tenang, perawat dapat membantu klien dan keluarga untuk mampu menerima kekurangan dari pengaturan yang ideal. Namun perawat harus mampu untuk melakukan upaya mengurangi kebisingan, cahaya lampu, dan pengaturan suhu ruangan dalam rangka memfasilitasi lingkungan yang meningkatkan kesehatan klien (Kolcaba, K., \&DiMarco 2005; Wong, J. Y., \& Earl 2009)

Secara psikologis, seorang ibu yang didukung suami atau keluarga akan lebih termotivasi untuk memberikan ASI kepada bayinya (Sari, 2011). Februhartanty (2008) 
mengemukakan bahwa untuk memenuhi ASI diperlukan adanya keharmonisan hubungan pola menyusui tripartit, yaitu antara ayah, ibu, dan bayi.

Keberhasilan menyusui sangat ditentukan oleh peran ayah karena ayah akanturut menentukan kelancaran refleks pengeluaran ASI yang sangat dipengaruhi oleh keadaan emosi atau perasaan ibu. Ayah dapat berperan aktif dalam membantu ibu dalam memberikan ASI dengan memberikan dukungan-dukungan emosional dan bantuanbantuan praktis lainnya. Pengertian tentang perannya yang penting ini merupakan langkah pertama bagi seorang ayah untuk dapat mendukung ibu agar berhasil menyusui dini (Roesli 2001).

Seorang ayah punya peran penting dalam keberhasilan ibu menyusui.Perasaan dan semangat ibu untuk menyusui dan untuk terus memberikan yang terbaik bagi anaknya sangat bergantung pada peran ayah untuk terus menjaga suasana kondusif. Proses menyusui menjadi terhambat bila kondisi ayah dan ibu tidak harmonis, ibu tidak mendapat dukungan dari suami, tidak bisa berkomunikasi dengan baik, dan perasaan ibu yang tidak aman dan nyaman (Sari, 2011).Dukungan suami yang merupakan faktor pendukung dalam keberhasilan ASI Eksklusif merupakan suatu kegiatan yang bersifat emosional maupun psikologis yang diberikan kepada ibu menyusui dalam memberikan ASI. Hal ini berkaitan dengan pikiran, perasaan, dan sensasi yang dapat memperlancar produksi ASI (Roesli 2001).Suami merupakan orang terdekat bagi ibu menyusui yang diharapkan selalu ada di sisi ibu dan selalu siap memberi bantuan.Keberhasilan ibu dalam menyusui tidak terlepas dari dukungan yang terusmenerus dari suami. Jika ibu mendapatkan kepercayaan diri dan mendapat dukungan penuh dari suami, motivasi ibu untuk menyusui akan meningkat (Sari, 2011).

\section{BAHAN DAN METODE}

Penelitian ini menggunakan jenis penelitian eksplanatif observasional. Jenis penelitian eksplanatif observasional bertujuan mengumpulkan data responden untuk menjawab isu strategis yang sedang terjadi, yang menyebabkan ibu postSC tidak melaksanakan IMD.Rancangan yang digunakan adalah cross sectional, dimana variabel sebab dan akibat diukur dalam waktu yang bersamaan(Supriyanto dan Djohan 2011).Respondent: 282 ibu post SC yang memenuhi kriteria inklusi dan eksklusi. Sampel dalam penelitian ini ibu post SC yang memenuhi kriteria inklusi dan eksklusi. Kriteria inklusi usia kehamilan $\geq 37$ minggu, Ibu dengan anastesi SAB, Ibu bersedia menjadi responden, Puting susu menonjol, IndikasiSC bukan karenaPEB/Eklamsi, kelainan jantung dan asma. Kriteria eksklusi dalam penelitian ini adalah bayi dengan kelainan kongenital, Bayi lahir dengan keadaan tidak bugar, Ibu dengan komplikasi $S C$. Penelitian ini dilakukan di ruang operasi (OK) kebidanan rumah sakit Tipe B, yaitu RSUD Jombang dan RSUD Sogaten Madiun.

\section{RESULTS}

Peran ayah dalam keberhasilan program IMD pada bayi yang lahir secara SC terdiri dari 2 indikator, yaitu dukungan ayah dan interaksi ayah.Hampir semua ayah mendukung ibu dalam melaksanakan IMD meskipun persalinannya secara SC. Tetapi pelaksanaan IMD masih tetap rendah.

Tabel 1. Tabel distribusi frekuensi dukungan ayah pada ibu SC dalam melaksanakan IMD.

\begin{tabular}{llcccccc}
\hline No & Indikator & \multicolumn{2}{c}{ IMD } & \multicolumn{2}{c}{ Tidak IMD } & \multicolumn{2}{c}{ Total } \\
\hline & Dukungan ayah: & (f) & $(\%)$ & $(\mathrm{f})$ & $(\%)$ & $(\mathrm{f})$ & $(\%)$ \\
\cline { 2 - 8 } 1. & Kurang & 0 & 0 & 3 & 100 & 3 & 100 \\
2. & Cukup & 10 & 3,6 & 268 & 96,4 & 278 & 100 \\
3. & Baik & 1 & 100 & 0 & 0 & 1 & 100 \\
\hline
\end{tabular}

Tabel 2: Tabel distribusi frekuensi interaksi ayah pada ibu SC dalam melaksanakan IMD

\begin{tabular}{llcccccc}
\hline No & \multicolumn{1}{c}{ Indikator } & \multicolumn{3}{c}{ IMD } & \multicolumn{2}{c}{ Tidak IMD } & \multicolumn{3}{c}{ Total } \\
\cline { 2 - 8 } & & (f) & $(\%)$ & $(\mathrm{f})$ & $(\%)$ & $(\mathrm{f})$ & $(\%)$ \\
\hline & Interaksi ayah: & & & & & & \\
1. & Kurang & 0 & 0 & 0 & 0 & 0 & 0 \\
2. & Cukup & 0 & 0 & 1 & 100 & 1 & 100 \\
3. & Baik & 11 & 4 & 270 & 96 & 281 & 100 \\
\hline
\end{tabular}


Seluruh ibu yang kurang mendapatkan dukungan ayah dalam melaksanakan IMD, tidak melaksanakan IMD.Ibu yang mendapatkan dukungan ayah dalam pelaksanaan IMD, melaksanakan IMD.Hampir semua ibu memiliki interaksi yang baik dengan ayah, tetapi mayoritas ibu tidak melaksanakan IMD, yakni sebesar $96 \%$.

Metode analisa statistik yang digunakan adalah analisa regresi linier berganda. Analisa regresi linier berganda adalah analisa statistik yang digunakan untuk menguji pengaruh variabel independen terhadap variabel dependen, dimana jumlah variabel independen lebih dari satu, dan variabel dependen berjumlah satu. Berdasarkan deskripsi variabel diatas, maka diketahui variabel dukungan suami (X1) dan interaksi suami (X2) merupakan variabel mempengaruhi (independent variable), sedangkan pelaksanaan IMD (Y) yang merupakan variabel dipengaruhi (dependent variable).

Hasil pengujian uji-t terhadap variabel dukungan suami (X1) didapatkan t-hitung 3,270 dimana nilai Sig. 0,001 dengan tingkat signifikansi $(\alpha)=5 \%$. Berdasarkan kriteria pengujian jika nilai Sig. $<\alpha$ maka disimpulkan terdapat pengaruh signifikan variabel dukungan suami terhadap pelaksanaan IMD. Hasil pengujian uji-t terhadap variabel interaksi suami (X2) didapatkan t-hitung 1,465 dimana nilai Sig. 0,144 dengan tingkat signifikansi $(\alpha)=5 \%$. Berdasarkan kriteria pengujian jika nilai Sig. $>\alpha$ maka disimpulkan tidak terdapat pengaruh signifikan variabel interaksi suami (X2) terhadap pelaksanaan IMD (Y). Hasil pengujian uji-t terhadap konstanta didapatkan t-hitung 2,901 dimana nilai Sig. 0,004 dengan tingkat signifikansi $(\alpha)$ $=5 \%$. Berdasarkan kriteria pengujian jika nilai Sig. $<\alpha$ maka disimpulkan terdapat pengaruh signifikan konstanta terhadap pelaksanaan IMD (Y).

Berdasarkan hasil pengujian individu terhadap masing-masing variabel dukungan ayah (X1), interaksi ayah (X2), dan konstantan, maka disimpulkan hanya interaksi ayah (X2) yang tidak signifikan berpengaruh terhadap pelaksanaan IMD (Y). Variabel yang signifikan berpengaruh yakni konstanta dan dukungan ayah (X1) yang memiliki nilai koefisien yakni sebesar 0,809 yang merupakan koefisien konstanta regresi, dan nilai 0,346 yang merupakan koefisien variabel dukungan suami (X1). Sehingga selanjutnya didapatkan persamaan regresi $\mathrm{Y}=0,809+0,346 \mathrm{X} 1$
Konstantan sebesar 0,809 menyatakan bahwa jika tidak ada dukungan ayah ( jika X1 bernilai nol), maka pelaksanaan IMD memiliki nilai sebesar 0,809. Koefisien regresi X1 sebesar 0,346 menyatakan bahwa setiap peningkatan dukungan ayah sebesar satu satuan, maka akan meningkatkan pelaksanaan IMD sebesar 0,346 satu satuan.

Berdasarkan hasil pengolahan didapatkan nilai $\mathrm{R}$-square sebesar 0,037 . Hal ini berarti sekitar 3,7\% pelaksanaan IMD (Y) dapat dijelaskan oleh dukungan ayah (X1). Sedang sisanya 96,3\% dijelaskan oleh variabel-variabel lainnya.

\section{PEMBAHASAN}

Faktor ayah dijelaskan oleh dua indikator yaitu dukungan ayah dan interaksi ayah-ibu. Hasil penelitian menunjukan mayoritas ayah memberikan dukungan cukup terhadap ibu yang melahirkan secara $S C$. Hampir semua ayah-ibu memiliki interaksi yang baik. Faktor dukungan ayah membuktikan mampu meningkatkan pelaksanaan IMD pada ibu bersalin secara SC.

Suami atau pasangan intim (father or intimate partnert), berdasarkan teori keperawatan Mercer berkontribusi pada proses pencapaian peran ibu yang pada pelaksanaannya tidak bisa digantikan oleh orang lain. Interaksi ayah membantu mengurangi tekanan dan memfasilitasi pencapaian peran ibu (Nursalam 2013).

Mercer, R. T., \& Ferkehch (1990) mengidentifikasi bahwa dukungan emosional dan penghargaan yang dimaksud adalah perasaan mencintai, penuh perhatian, percaya dan mengerti, tentang peran pelaksanaan, dan bagaimana ia menampilkan perannya. Dukungan instrumental sebagai pertolongan yang langsung seperti membantu merawat bayi serta dukungan informasional untuk membantu individu menolong dirinya sendiri dengan memberikan informasi yang berguna dan berhubungan dengan masalah dan atau situasi.

Secara psikologis, seorang ibu yang didukung ayah atau keluarga akan lebih termotivasi untuk memberikan ASI kepada bayinya (Sari, 2011). Februhartanty (2008) mengemukakan bahwa untuk memenuhi ASI diperlukan adanya keharmonisan hubungan pola menyusui tripartit, yaitu antara ayah, ibu, dan bayi. Keberhasilan menyusui sangat ditentukan oleh peran ayah karena ayah akan turut menentukan kelancaran refleks pengeluaran ASI yang sangat dipengaruhi olehkeadaan emosi atau perasaan ibu. Ayah dapat berperan aktif dalam membantu ibu 
dalam memberikan ASI dengan memberikan dukungan-dukungan emosional dan bantuanbantuan praktis lainnya. Pengertian tentang perannya yang penting ini merupakan langkah pertama bagi seorang ayah untuk dapat mendukung ibu agar berhasil menyusui dini (Roesli 2001).

Seorang ayah punya peran penting dalam keberhasilan ibu menyusui. Perasaan dan semangat ibu untuk menyusui dan untuk terus memberikan yang terbaik bagi anaknya sangat bergantung pada peran ayah untuk terus menjaga suasana kondusif. Proses menyusui menjadi terhambat bila kondisi ayah dan ibu tidak harmonis, ibu tidak mendapat dukungan dari ayah, tidak bisa berkomunikasi dengan baik, dan perasaan ibu yang tidak aman dan nyaman (Sari, 2011).

Dukungan ayah yang merupakan faktor pendukung dalam keberhasilan ASI Eksklusif merupakan suatu kegiatan yang bersifat emosional maupun psikologis yang diberikan kepada ibu menyusui dalam memberikan ASI.Hal ini berkaitan dengan pikiran, perasaan, dan sensasi yang dapat memperlancar produksi ASI (Roesli 2001).Ayah merupakan orang terdekat bagi ibu menyusui yang diharapkan selalu ada di sisi ibu dan selalu siap memberi bantuan.Keberhasilan ibu dalam menyusui tidak terlepas dari dukungan yang terusmenerus dari suami. Jika ibu mendapatkan kepercayaan diri dan mendapat dukungan penuh dari suami, motivasi ibu untuk menyusui akan meningkat (Sari, 2011).

Keterlibatan seorang ayah dalam pelaksanaan IMD akan memberi motivasi ibu dan menentukan kestabilan emosi ibu. Kondisi emosi yang stabil menentukan sikap positif ibu. Kestabilan tersebut bisa diraih bila sang ayah atau keluarga memberikan dukungan atau motivasinya secara maksimal. Dukungan memberikan suatu kesan bahwa ia dicintai dan diperhatikan, memiliki harga diri dan dihargai sehingga dengan sendirinya akan berpengaruh terhadap emosional ibu dimana ia lebih tenang, nyaman (Lumula, et. al, 2012). Selain itu, ayah didukung untuk mengenali perilaku bayi sebelum menyusu.Hal ini dapat berlangsung beberapa menit atau satu jam. Dukungan ayah akan meningkatkan rasa percaya diri ibu (Roesli 2001).

Pada kenyataannya, hal ini sesuai karena aya tidak diperbolehkan mendampingi istrinya di kamar operasi terutama saat di ruang operasi, sehingga dukungan yang diberikan ayah tidak maksimal. Padahal dukungan ayah selama di kamar operasi diperlukan untuk meningkatkan percaya diri ibu dalam melaksanakan IMD. Sehingga dapat disimpulkan bahwa meskipun ibu mendapatkan dukungan ayah, tetapi ayah tidak berada disisi ibu saat operasi menyebabkan ibu tidak mampu melaksanakan IMD.

\section{SIMPULAN DAN SARAN}

\section{Simpulan}

Variabel dukungan ayah berpengaruh signifikan terhadap pelaksanaan IMD. Semakin baik dukungan ayah tentang pelaksanaan IMD pada ibu, semakin meningkatkan pelaksanaan IMD, sedangkan variabel interaksi ayah tidak berpengaruh signifikan terhadap pelaksanaan IMD.Interaksi ayah dan ibu tidak mempengaruhi pelaksanaan IMD.

\section{Saran}

Dukungan ayah saat ibu SC sangat diperlukan untuk meningkatkan pelaksanaan IMD. Perlu dilakukan penelitian lagi untuk mengetahui faktor lain yang mampu meningkatkan pelaksanaan IMD.

\section{KEPUSTAKAAN}

Alligood, M.R., 2002. A Theory of the art of nursing discovered in Rogers' Science of Unitary Human Beings. International Journal for Human Caring, 6, pp.55-60.

Kolcaba, K., \&DiMarco, M.A., 2005. Comfort Theory and its application to pediatric nursing. Pediatric nursing, 31(3), pp.187-194.

Mercer, R. T., \&Ferkehch, S.L., 1990. Predictors of parental attachment during early parenthood. Journal of Advanced Nursing, 15(3), pp.268-280.

Nursalam, 2013. Metodologi Penelitian Ilmu Keperawatan: Pendekatan Praktis 3rd ed., Jakarta: Salemba Medika.

Padmavathi, P., Jayadeepa, T., \&Babu, A.A., 2014. Initiation of Breast Feeding After Caesarian Deliver. Asian Journal of Nursing Education and Research, 4(1), p.114.

Prior, E., Santhakumaran, S., Gale, C., Philipps, L. H., Modi, N., \& Hyde, M.J., 2012. Breastfeeding after cesarean delivery: a systematic review and metaanalysis of world literature. American 
Jurnal Ners Vol. 11 No. 2 Oktober 2016: 224 - 229

Journal of Clinical Nutrition, 95(5), pp.1113-1135.

Roesli, 2001. Bayi Sehat Berkat ASI Eksklusif, Jakarta: PT ElexKomputindo.

Sari, Reni, (2011). Hubungan Karakteristik, Sikap, dan Dukungan Ayah terhadap pemberian ASI Eksklusif di Puskesmas Takang Kabupaten Solok Tahun 2014.

Supriyanto dan Djohan, 2011. Metodologi Riset Bisnis dan Kesehatan, Kalimantan: PT Grafika Wangi.

Wong, J. Y., \& Earl, J.K., 2009. Towards an integrated model of individual, psychosocial, and organizational predictors of retirement adjustment. Journal of Vocational Behavior, 75(1), pp.1-13. 